NBER WORKING PAPER SERIES

\title{
BETTER LUCK NEXT TIME: LEARNING THROUGH RETAKING
}

\author{
Verónica Frisancho \\ Kala Krishna \\ Sergey Lychagin \\ Cemile Yavas \\ Working Paper 19663 \\ http://www.nber.org/papers/w19663
}

\author{
NATIONAL BUREAU OF ECONOMIC RESEARCH \\ 1050 Massachusetts Avenue \\ Cambridge, MA 02138 \\ November 2013
}

We are grateful to the Center for University Selection and Placement (O SYM) for providing the data. We would also like to thank Dilara Bakan Kalaycoglu for answering all our questions about the data and Quang Vuong and Susumu Imai for extremely useful conversations. We are also indebted to participants of the Pacific Conference for Development Economics 2011, the 10th Journees Louis-André Gérard-Varet Conference in Public Economics, the LACEA 2012 Annual Meeting, the 2012 Seminar Series at the Copenhagen Business School, the 8th Annual Conference on Economic Growth and Development at ISI Delhi, and the 2012 Asian Meeting of the Econometric Society for suggestions and comments. Kala Krishna would like to thank the Human Capital Foundation (www.hcfoundation.ru), and especially Andrey P. Vavilov, for support of the Department of Economics at Penn State University. The views expressed herein are those of the authors and do not necessarily reflect the views of the National Bureau of Economic Research.

At least one co-author has disclosed a financial relationship of potential relevance for this research. Further information is available online at http://www.nber.org/papers/w19663.ack

NBER working papers are circulated for discussion and comment purposes. They have not been peerreviewed or been subject to the review by the NBER Board of Directors that accompanies official NBER publications.

(C) 2013 by Verónica Frisancho, Kala Krishna, Sergey Lychagin, and Cemile Yavas. All rights reserved. Short sections of text, not to exceed two paragraphs, may be quoted without explicit permission provided that full credit, including (C) notice, is given to the source. 
Better Luck Next Time: Learning Through Retaking

Verónica Frisancho, Kala Krishna, Sergey Lychagin, and Cemile Yavas

NBER Working Paper No. 19663

November 2013

JEL No. C13,C38,I23,I24

\section{$\underline{\text { ABSTRACT }}$}

In this paper we provide some evidence that repeat taking of competitive exams may reduce the impact of background disadvantages on educational outcomes. Using administrative data on the university entrance exam in Turkey we estimate cumulative learning between the first and the nth attempt while controlling for selection into retaking in terms of observed and unobserved characteristics. We find large learning gains measured in terms of improvements in the exam scores, especially among less advantaged students.

Verónica Frisancho

Research Department

Inter-American Development Bank (IADB)

1300 New York Ave. NW

Washington, DC 20577

vfrisancho@iadb.org

Kala Krishna

Department of Economics

523 Kern Graduate Building

The Pennsylvania State University

University Park, PA 16802

and NBER

kmk4@psu.edu
Sergey Lychagin

Department of Economics

Central European University

Nador u. 9

Budapest 1051

Hungary

lychagins@ceu.hu

Cemile Yavas

cemileyavas@gmail.com 


\section{Introduction}

A central question in education policy is how to reduce the dependence of educational outcomes on background. In this paper we provide evidence that repeat taking of entrance exams might have some promise in this regard. Using administrative data on the university entrance exam (ÖSS) in Turkey we estimate cumulative learning in repeated attempts, while controlling for selection into retaking in terms of observed and unobserved characteristics. Our contribution is twofold. First, we provide a simple way to estimate learning gains among retakers despite only having cross-sectional data. Second, we find large learning gains, measured in terms of improvements in the entrance exam scores, especially among less advantaged students.

We use administrative data on a random sample of about 115,000 ÖSS applicants (of which only about a third are first time takers) from three high school tracks (Science, Social Studies, Turkish/Math). Estimating learning gains from retaking is particularly challenging for us as we cannot follow students as would be possible with panel data. However, we overcome this limitation using information on repeat takers along with a rich set of performance measures. Our approach controls for selection into retaking and teases out average cumulative learning between the first and $n^{\text {th }}$ attempts.

Our model's key assumptions are i) students know their own ability though it is unobserved by the econometrician, ii) learning is a draw from a distribution that is allowed to vary with observables and/or unobservables, and iii) performance in high school and on the entrance exam is partly determinate, coming from observables and unobserved ability, and partly random. We take a factor approach where the factors are the random performance shocks and the unobserved ability. In our model ability will drive the correlation between high school grade point average (GPA) and raw verbal and quantitative exam scores once the effect of observables is netted out.

We find important cumulative learning gains among repeat takers once selection into retaking is controlled for. For example, we find that learning gains in the second attempt fluctuate around $5 \%$ of the predicted initial score, irrespective of the track. In the Social Studies and TurkishMath tracks, we identify larger and increasing cumulative gains as the number of attempts 
increases. Gains in these two tracks on higher order attempts range from $8 \%$ to $14 \%$ of the predicted initial score.

Most important, we identify larger gains among repeat takers from less advantaged backgrounds: in all tracks, students who come from public schools and households in the lowest income category experience larger learning gains than more privileged students from elite schools or higher income households. These results suggest that disadvantaged students can meet high admission standards though it may take them multiple attempts to do so. Although in this paper we do not (and cannot) measure the net welfare impact of allowing retaking, our results draw attention to the benefits that systems like the Turkish one, similar to that in much of continental Europe, Asia, and some Latin American countries, may generate for repeat takers.

While we focus on the Turkish experience, the issues we study are far more general. Most countries rely on different admissions systems to place students. The extent to which they rely exclusively on an exam or on a more diverse spectrum of student characteristics varies considerably. In the US, for example, the SAT or ACT is widely used. However, performance on these exams is only a small part of what colleges use in admissions decisions. Extracurricular activities, alumni ties, interviews, the perceived likelihood of the student coming, and donations may matter even more than the student's performance. As long as these factors favor more privileged students, such an allocation system will tend to perpetuate socioeconomic inequalities. By eliminating the direct influence of socioeconomic status on school placement, the Turkish system offers a way to level the playing field for less advantaged students. Moreover, though students' backgrounds will still have an effect on performance indirectly, allowing multiple attempts may enable less prepared but able students to catch up and reduce the role of background inequalities on college admissions outcomes.

The paper proceeds as follows. Section 2 relates our work to the literature. Section 3 describes the institutional context and the data. The model and the econometric methodology are presented in Section 4 while Section 5 presents the results. Finally, Section 6 concludes and lays out some avenues for future research. 


\section{Related Literature}

By documenting that the learning gains of repeat taking are higher for more disadvantaged students, our paper relates to two strands of literature on educational catch-up.

The first of these strands looks at the issue of catch-up by immigrants. Portes and Rumbaut (2001) found that immigrant children who arrive before age 13 and second generation children in Miami and San Diego tend to perform better than their native-born schoolmates in terms of grades, rates of school retention, and behavioral aspects (e.g., doing homework). However, those who arrive after age 13 tend to be outperformed by native-born students. Using the 1995-2002 Current Population Surveys (CPS), Card (2005) finds some evidence in favor of educational catch-up among second generation migrants. While immigrants have about $1.2-1.4$ fewer years of education than natives, second generation immigrants have 0.3-0.4 more years of schooling than people whose parents were born in the US.

The second strand, which focuses on disadvantaged groups favored by affirmative action (AA), presents a less rosy picture. In general, rather than catching-up, the beneficiaries of AA preferences seem to fall behind. Sander (2004) finds that the average performance gap between blacks and whites at selective law schools is large and, more importantly, tends to get larger as both groups progress through school. Arcidiacono et al. (2012) shows that the GPA gap between white and black students at Duke University falls by half between the first and the last year of college, but this comes primarily from smaller variance in grading during later years and a higher proportion of black students switching into easier majors. If weaker students choose easier courses and this self-selection is not taken into account, one might incorrectly interpret a reduction in the academic gap between strong and weak students as catch-up. Loury and Garman (1993, 1995) make a related point. In settings where course selection issues are minimized, students given preferences seem to fall behind. Frisancho and Krishna (2012) look at the Indian higher education setting which has transparent admission criteria and a rigid course structure as well as significant affirmative action. They find that backward groups fall behind, and more so in more selective majors where the initial gap is greater. 
In our setting, the exam covers the same set of subjects and has the same level of difficulty across cohorts. This generates two advantages: i) we do not have to deal with self-selection into majors and courses and ii) it is easier to catch up in our setting than in the AA case. The beneficiaries of AA admission policies start college lacking prerequisite knowledge and cannot benefit from college-level courses to the same extent as their more prepared peers. Consequently, even by running as fast as they can, these students can hope, at best, to stay in the same place they started.

Although relatively scarce, there have been previous attempts to measure catch-up in an environment similar to ours, that is, in the period between high school graduation and college enrollment. Nathan and Camara (1998) shows that $55 \%(35 \%)$ of the juniors taking the SAT in the US improved (worsened) their scores as seniors. Vigdor and Clotfelter (2003) use data on undergraduate applicants to three selective US research universities to look at the evolution of SAT scores over multiple attempts. They implement a two-stage Heckman sample-selection procedure and estimate that between $70 \%$ and $90 \%$ of the observed score increase remains when selection is accounted for.

Although the contribution of the work on SATs is important, there are two important disadvantages compared to the ÖSS. First, as the SATs are one of many things that matter for university admissions, students take them more lightly, generating noisier measures of performance. Second, the level of difficulty of the SAT is far below that of the ÖSS, with the SAT being more of an IQ test than a skills test. This compromises its ability to distinguish between takers, especially at the high end. Thus, we argue that our data provides important advantages to looking for evidence on catch-up and measuring learning among repeat takers.

Our methodology imposes a factor structure on performance outcomes in high school and on the admission exam. Net of the effects of observables, GPA and exam scores are determined by two factors: students' ability and randomness. Following Carneiro et al. (2003), many papers have relied on this structure to model educational outcomes 1

\footnotetext{
${ }^{1}$ See for example, Coolev et al. (2011).
} 


\section{Turkish Context}

\subsection{Institutional Background}

In Turkey, entrance to higher education institutions is regulated by the ÖSS (Student Selection Exam), a national examination administered by the Student Selection and Placement Center (ÖSYM) on an annual basis. All high school seniors and graduates are eligible to take it and there is no limit on the number of retakes 2 Even though centralized admission systems are common in other places in Europe as well as Asia and Latin America, the Turkish setting is particularly interesting due to the high share of repeat takers in the pool of applicants. For instance, in 2002 roughly one-third of the exam takers were high school seniors, the remainder being repeat takers 3 Although the high ratio of retakers coupled with a low placement rate seems wasteful, there may be some hidden benefits of the current setup.

The college placement exam is composed of multiple choice questions with negative marking for incorrect answers. Students' performance is evaluated in four subjects: Mathematics, Turkish, Science, and Social Studies. The raw scores in these four subjects are then used to calculate raw verbal scores, defined as the sum of the scores in Turkish and Social Studies, and raw quantitative scores, defined as the sum of Science and Math. All the raw scores are standardized and used to construct three weighted scores 4 Students who obtain more than 105 in any weighted score are eligible to submit preferences for two year schools or distance education programs. To be able to submit preferences for four year programs, a minimum score of 120 is required.

Students choose a track while in high school; for the most part, the choice is between Sciences, Social Studies, and Turkish-Math. The college placement process is designed to encourage students to apply to programs that build on their high school education 5 Depending on the college program chosen by the student, only one of the three weighted scores will be relevant. This setup enables us to focus on a single weighted score for each track, which we call the relevant

\footnotetext{
${ }^{2}$ See Türk Ĕ̆itim Derneği (TED or Turkish Educational Association) for more details on this exam.

${ }^{3}$ The most recent ratio of high school seniors to total candidates, although higher, is still quite low: in 2013, there were about 800,000 high school seniors among 1.9 million applications.

${ }^{4}$ For details, see Appendix A

${ }^{5}$ For example, the high school GPA of someone from the Science track is given less weight if he applies to a program compatible with another track.
} 
exam score in the following sections. ÖSYM also calculates placement scores for each subject, which are a combination of the weighted scores and a standardized measure of the student's high school GPA 6

Once the applicant learns his scores, he submits a list of his program preferences, having complete information on the previous year's cut-off scores for each program (i.e., the score of the last student admitted). Placement is merit based: a student is placed in his most preferred program, conditional on the availability of seats after all the applicants with higher scores are placed. Students fail to be placed if they do not pass the exam or if other students with better scores fill up all the available seats in the programs on their preference list. These students will have the option of retaking the exam with no penalties. Students who are placed are also allowed to retake, but their placement score is penalized if they retake the following year.

\subsection{Data}

Our data covers a random sample of about 120,000 students who took the ÖSS in 2002. After cleaning the data and dealing with some minor inconsistencies, we lose $3.9 \%$ of the observations so that our final cross section covers 114,800 applicants from the Science $(38,771)$, Turkish-Math $(38,571)$, and Social Studies tracks $(37,458)$.

ÖSYM data comes from four sources: students' application forms, a survey applied in 2002, high school records, and administrative records. For each student, our database contains information on high school characteristics (track and type of school), high school GPA, standing at the time of the exam (high school senior, repeat taker, graduated from another program, among other options), individual and background characteristics (gender, household income, parents' education and occupation, family size, time and money spent on private tutoring, and number of previous attempts), and performance outcomes (raw scores, weighted scores, and placement outcomes). Since we want to measure high school performance across schools, we construct quality normalized GPAs to control for quality heterogeneity and grade inflation across high

\footnotetext{
${ }^{6}$ This standardization is implemented by the ÖSYM to make GPAs comparable. A detailed description of this process is provided in Appendix A
} 
schools (see Appendix $B$ for details) 7

\subsection{Preliminary Evidence}

The measurement of learning gains among repeat takers would be a straightforward exercise with longitudinal data. However, the ÖSS data only provides us with a cross-section of applicants, both first time takers as well as repeat takers.

Although the scores of repeat takers will contain information on learning relative to their first attempt, it is hard to isolate these gains without a counterfactual. Notice that the exam scores of repeat takers reflect two effects: learning and selection into retaking. Learning shifts the distribution of scores to the right over attempts while selection, which is an endogenous process, can shift it to the right or to the left depending on who retakes.

Figure 1: Distribution of Exam Scores by Track
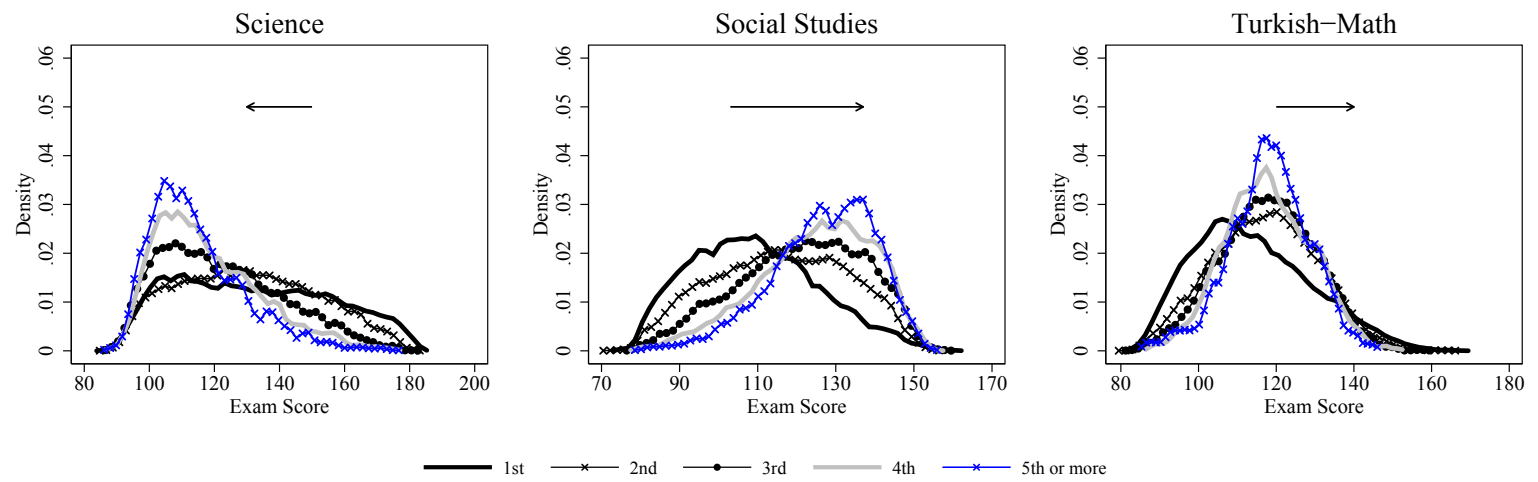

Figure 1 plots the empirical distributions of exam scores by number of attempts and track.

In general, there is some evidence of compression in the distributions as the number of attempts increases. Yet, two distinct patterns emerge. In the Science track the distribution of scores shifts to the left, consistent with worse students selecting into retaking and limited learning. In

\footnotetext{
${ }^{7}$ It is worth noting that very few papers have explored the Turkish data set. Tansel and Bircan (2005) studies the determinants of attendance at private tutoring centers and its effects on performance. Savgin (2011) looks at the gender gap in college. Moreover, Caner and Okten (2010) looks at career choice using data on preferences while Caner and Okten (2013) examines how the benefits of publicly subsidized higher education are distributed among students with different socioeconomic backgrounds.
} 
turn, the score distribution moves to the right in Turkish-Math and Social Studies. This could suggest sizeable learning gains but selection could be operating in either direction.

A further look into the data identifies a pattern common to all tracks. Figure 2 presents exam score distributions by number of attempts and high school GPA quartiles. In all tracks, first time takers do worse than repeat takers in the lowest GPA quartiles but this pattern reverses as GPA increases. This suggests that weaker students learn more 8 If better performing students are disproportionately found in the Science track, Figure 1 could reflect a composition effect due to differential learning and selection across tracks.

Table C.1 shows that this is the case. We find stronger students in the Science track, where the average standardized high school GPA is 51.7 as compared to 49 and 47.7 in Turkish-Math and Social Studies respectively. Science track students also seem to be better off than Social Studies and Turkish-Math students in terms of other background characteristics: they have more educated and wealthier parents. They also tend to come from better schools and have higher access to prep schools and/or tutoring while in high school.

The next section develops a simple dynamic model of learning and repeat taking to help us understand the biases that selection introduces. In light of this model, we then develop our estimation strategy.

\section{Model}

In this section we lay out a simple model and our estimation strategy. We show that while students select into retaking based on ability and performance shocks on the entrance exam, GPA performance shocks do not affect retaking when students are very patient. Based on this, we lay out a strategy to identify and measure learning effects relying only on cross-sectional data.

\footnotetext{
${ }^{8}$ This pattern is also shown in Vigdor and Clotfelter (2003) among SAT repeat takers, suggesting that initially better performing students have the lowest learning gains.
} 
Figure 2: Distribution of Exam Scores by GPA quartiles and Track
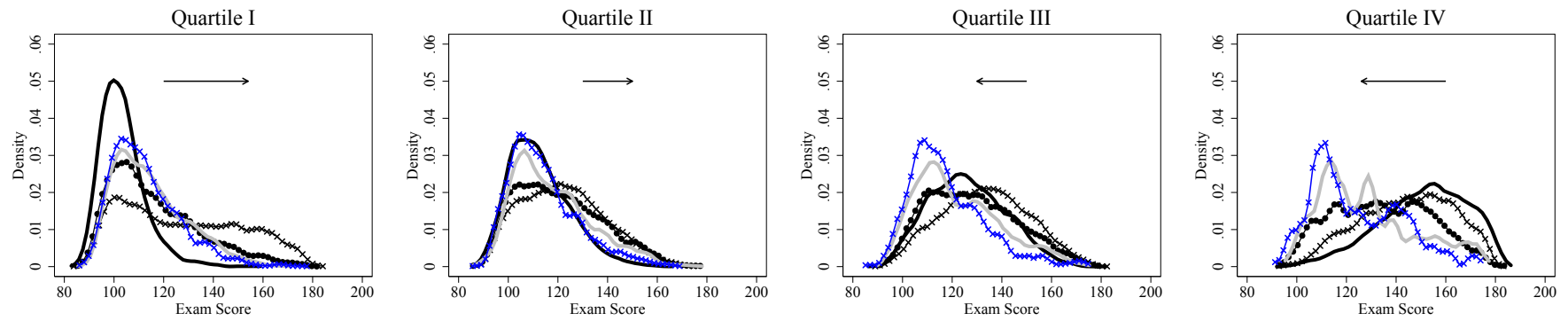

(a) Science
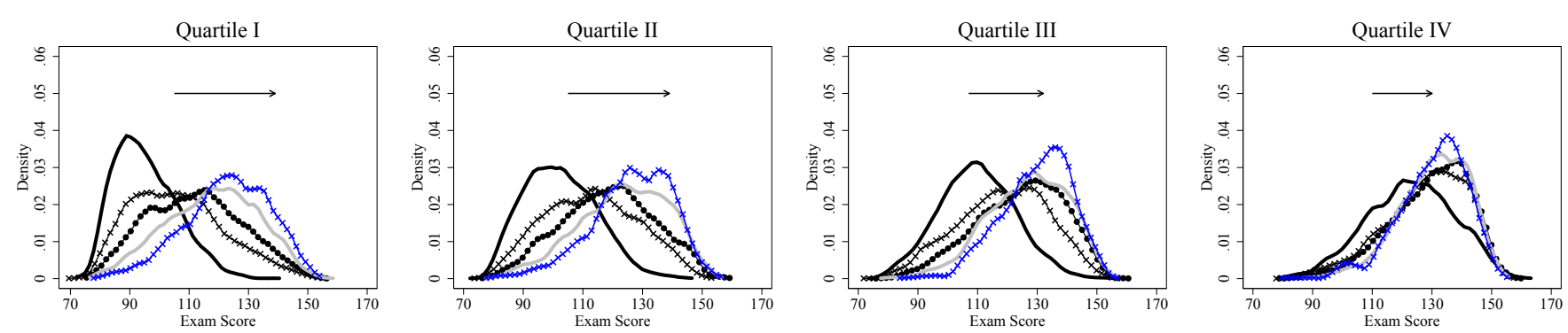

(b) Social Studies
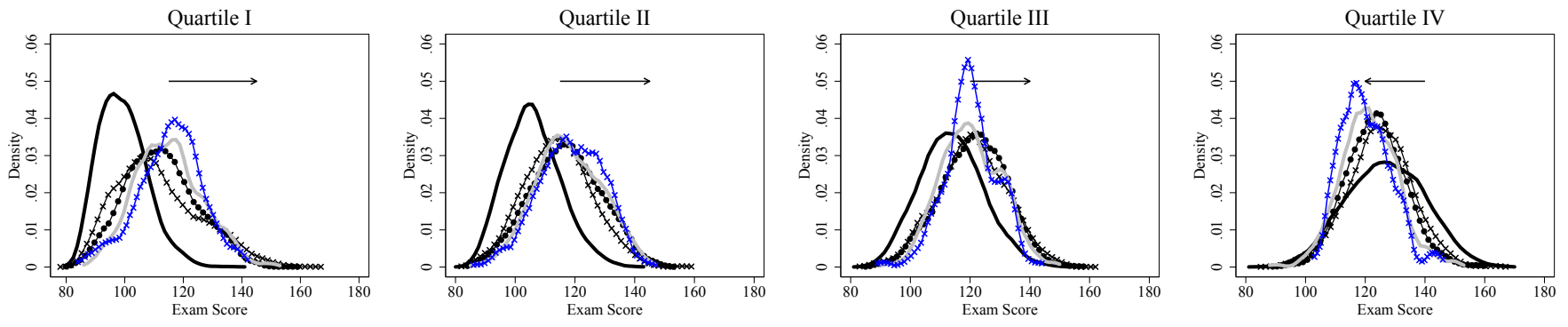

(c) Turkish-Math 
Let $s_{*}$ denote the cut-off exam score for a candidate to be placed in a program 9 Although critical, the relevant exam score for student $i$ in his $n^{\text {th }}$ attempt, denoted by $s_{i n}$, is not all that determines placement (see Section 3.2). For students with exam scores above $s_{*}$, placement scores are obtained as a weighted average of the exam score, $s_{i n}$, and high school GPA, $g_{i}$. We assume the system has a continuum of college qualities. Since students with higher scores have more options open to them, they will obtain higher utility. Normalizing the weight on exam scores to one, the instantaneous college utility is specified as follows:

$$
u\left(s_{i n}, g_{i}\right)= \begin{cases}-\infty & \text { if } s_{i n}<s_{*} \\ s_{i n}+\eta g_{i} & \text { if } s_{i n} \geq s_{*}\end{cases}
$$

Students with a score below $s_{*}$ (the cutoff for being eligible) cannot be placed according to the rules. We set their utility from being placed at $-\infty$ to reflect the impossibility of placement while those with a cutoff above $s_{*}$ choose between being placed, retaking, and quitting.

We assume that student $i$ 's high school GPA is given by:

$$
g_{i}=X_{i} \alpha_{0}+\theta_{i}+\varepsilon_{i 0}
$$

where $\varepsilon_{i 0}$ is a random shock. The term $X_{i} \alpha_{0}$ captures the effect of observables on the GPA while $\theta_{i}$ is an individual-specific component that captures the ability of the student. Both the effect of observables and ability are known to the student, but $\theta_{i}$ is unobserved by the researcher 10

As described in the data section, the exam score comes from the performance on the verbal and quantitative sections of the exam, appropriately weighted. Let $s_{i n q}$ and $s_{i n v}$ denote the student's quantitative and verbal scores respectively, and $\omega_{q}$ and $\omega_{v}$ be fixed known weights:

$$
\begin{aligned}
& s_{i n q}=X_{i} \alpha_{1 q}+\beta_{q} \theta_{i}+\Lambda_{i n q}+\varepsilon_{i n q} \\
& s_{i n v}=X_{i} \alpha_{1 v}+\beta_{v} \theta_{i}+\Lambda_{i n v}+\varepsilon_{i n v}
\end{aligned}
$$

\footnotetext{
${ }^{9}$ As explained in Section 3 ÖSYM imposes a cut-off score to qualify for placement in university programs.

${ }^{10}$ The known ability assumption is reasonable in the Turkish context. Although the exam is taken in $12^{\text {th }}$ grade, students start preparing for this exam as early as $9^{\text {th }}$ grade. By the time they take the exam for the first time, they have already taken many practice exams and have a good idea of their expected performance.
} 
where $\Lambda_{i n j}$ is the cumulative learning in topic $j$ up to attempt $n 11$ We assume that students know their future learning shocks and let $\Lambda_{i n j}$ depend on $X_{i}$ and/or $\theta_{i}$. $\varepsilon_{i n j}$ is a random shock drawn from a density function common to all $n$ and $i$ for a given $j=v, q$. These transitory shocks are meant to capture chance occurrences that could affect exam performance (e.g., getting a question you did not expect) and are therefore assumed to be iid.

The exam score is a weighted average of the verbal and quantitative scores, and hence

$$
\begin{aligned}
s_{i n} & =\omega_{q} s_{i n q}+\omega_{v} s_{i n v} \\
& =X_{i} \alpha_{1}+\beta \theta_{i}+\Lambda_{i n}+\varepsilon_{i n} \\
& =\bar{s}_{i n}+\varepsilon_{i n} .
\end{aligned}
$$

The distribution of $\varepsilon_{i n}$ is given by $F($.$) for all i$ and $n$. After the student learns his score, he decides whether to retake, quit, or be placed. If he decides to retake, he pays a cost $\psi$ that is incurred immediately, though the results of retaking are apparent only a year later and so are discounted by $\delta$. Thus, the value of retaking is given by:

$$
V_{i n}\left(\bar{s}_{i n}, g_{i}, \boldsymbol{\Lambda}_{i}\right)=-\psi+\delta E_{\varepsilon_{i(n+1)}}\left(\max \left[V_{i(n+1)}\left(\bar{s}_{i(n+1)}, g_{i}, \boldsymbol{\Lambda}_{i}\right), u\left(s_{i(n+1)}, g_{i}\right), V_{Q}\right]\right)
$$

where $V_{Q}$ is the value of quitting and $\boldsymbol{\Lambda}_{i}$ is the vector of all the learning shocks in all retaking attempts.

\subsection{Selection Into Retaking}

Students who retake are those for whom retaking is better than the maximum of quitting and being placed. There is selection on $\varepsilon_{i 0}$ for those choosing between retaking and being placed as well as for those choosing between retaking and quitting. In this section, we use a simplified version of the model discussed above to understand the nature of the selection driven by $\varepsilon_{i 0}$.

When choosing between retaking and quitting, students with high $\varepsilon_{i 0}$ will be more likely to

\footnotetext{
${ }^{11}$ In what follows, we talk about raw quantitative and verbal scores for Science and Social Studies students as defined in Sub-Section 3.1. This is natural because the pair of subjects used to construct these raw scores get the same weight in the relevant weighted scores for these tracks. However, in the Turkish-Math track, we label as "quantitative" and "verbal" the sum of the Turkish and Math scores and the sum of the Science and Social Studies scores, respectively, to reflect equal weights of these pairs of subjects in the relevant weighted score.
} 
retake as a higher value of the GPA shock increases $V_{i n}$ without affecting $V_{Q}$. In other words, students with low $\varepsilon_{i 0}$ will quit. This makes the expected value of $\varepsilon_{i 0}$ among retakers positive, generating a negative bias in our learning estimates. As $\delta$ rises, $V_{i n}$ increases and more students retake, reducing, but possibly not eliminating, this negative bias.

On the other hand, when choosing between retaking and placement, students with high $\varepsilon_{i 0}$ will be less likely to retake and more likely to cash in their good GPA shocks. However, as we show below, as $\delta$ approaches unity, this effect fades away. At $\delta=1$, there is no selection on the basis of $\varepsilon_{i 0}$, and hence no positive bias.

Assume that there is no additional learning beyond the first retake, $\Lambda_{i n}=\lambda_{i 2} \equiv \lambda_{i}$. This assumption makes the problem stationary after the first period as the expected score for student $i$ is constant for each period $n \geq 2: \bar{s}_{i n} \equiv \bar{s}_{i}=X_{i} \alpha_{1}+\beta \theta_{i}+\lambda_{i}$. Let $\tilde{\varepsilon}_{i}$ be the shock that makes student $i$ just retake, i.e., $V_{i}=u\left(\bar{s}_{i}, g_{i}, \tilde{\varepsilon}_{i}\right)$. Given (10) and the definition of the instantaneous utility, $\tilde{\varepsilon}_{i}$ is defined by

$$
V_{i}=X_{i} \alpha_{1}+\beta \theta_{i}+\lambda_{i}+\tilde{\varepsilon}_{i}+\eta\left(X_{i} \alpha_{0}+\theta_{i}+\varepsilon_{i 0}\right)
$$

Given the stationary nature of the problem, $V_{i}$ is defined by

$$
V_{i}=-\psi+\delta F\left(\tilde{\varepsilon}_{i}\right) V_{i}+\delta \int_{\varepsilon=\tilde{\varepsilon}_{i}}\left(X_{i} \alpha_{1}+\beta \theta_{i}+\lambda_{i}+\varepsilon+\eta\left(X_{i} \alpha_{0}+\theta_{i}+\varepsilon_{i 0}\right)\right) f(\varepsilon) d \varepsilon
$$

Substituting for $V_{i}$ from (4) and rearranging gives

$$
\begin{aligned}
& \left(X_{i} \alpha_{1}+\beta \theta_{i}+\lambda_{i}+\tilde{\varepsilon}_{i}+\eta\left(X_{i} \alpha_{0}+\theta_{i}+\varepsilon_{i 0}\right)\right)\left(1-\delta F\left(\tilde{\varepsilon}_{i}\right)\right) \\
= & -\psi+\delta\left[1-F\left(\tilde{\varepsilon}_{i}\right)\right]\left[X_{i} \alpha_{1}+\beta \theta_{i}+\lambda_{i}+\eta\left(X_{i} \alpha_{0}+\theta_{i}+\varepsilon_{i 0}\right)\right]+\delta \int_{\varepsilon=\tilde{\varepsilon}_{i}} \varepsilon f(\varepsilon) d \varepsilon
\end{aligned}
$$

which yields

$$
\tilde{\varepsilon}_{i}\left(1-\delta F\left(\tilde{\varepsilon}_{i}\right)\right)=-\psi+\delta \int_{\varepsilon=\tilde{\varepsilon}_{i}} \varepsilon f(\varepsilon) d \varepsilon-(1-\delta)\left(X_{i} \alpha_{1}+\beta \theta_{i}+\lambda_{i}+\eta\left(X_{i} \alpha_{0}+\theta_{i}+\varepsilon_{i 0}\right)\right)
$$

At $\delta=1$ this reduces to

$$
\tilde{\varepsilon}_{i}\left(1-F\left(\tilde{\varepsilon}_{i}\right)\right)=-\psi+\int_{\varepsilon=\tilde{\varepsilon}_{i}} \varepsilon f(\varepsilon) d \varepsilon .
$$


Notice that for $\delta=1, \tilde{\varepsilon}_{i}$ is independent of $\varepsilon_{i 0}$, and hence $E\left(\varepsilon_{0} \mid n\right)=E\left(\varepsilon_{0}\right)=0$. The intuition is simple. When students are impatient, they want to cash in their high GPA so that students with high $\varepsilon_{i 0}$ are less likely to retake, i.e., $E\left(\varepsilon_{0} \mid n\right)<E\left(\varepsilon_{0}\right)=0$. As $\delta$ goes to one, this effect vanishes as is clear from looking at the derivative of (6) with respect to $\varepsilon_{i 0}$ :

$$
\frac{\partial \tilde{\varepsilon}_{i}}{\partial \varepsilon_{i 0}}=-\frac{(1-\delta)}{\left(1-\delta F\left(\tilde{\varepsilon}_{i}\right)\right)} \eta \leq 0
$$

In the extreme, when students are perfectly patient, the utility associated with their GPA shock is fixed over time and hence does not affect their decision to retake.

To summarize, there are two sources of selection on $\varepsilon_{i 0}$ among repeat takers. First, those with low $\varepsilon_{i 0}$ 's may choose to quit rather than retake which tends to make $E\left(\varepsilon_{0} \mid n\right)$ positive. Second, those with high $\varepsilon_{i 0}$ 's may choose to be placed rather than retake, which tends to make $E\left(\varepsilon_{0} \mid n\right)$ negative. The latter source of selection vanishes when students are patient enough while the former need not 12

\subsection{Taking the Model to the Data}

Of interest for estimation are equations (11), (2), and (3). To estimate learning, we need to find a way to obtain unbiased estimates of the $\alpha$ 's and $\beta$ 's which will let us control for selection into retaking. This is what we turn to now.

In the model, there are four factors, $\left(\theta_{i}, \varepsilon_{i 0}, \varepsilon_{i n q}, \varepsilon_{i n v}\right)$, that affect the various performance measures. The factor loadings, $\beta_{q}$ and $\beta_{v}$ in (2) and (3), respectively, allow $\theta_{i}$ to have a differential effect across performance measures. The other three factors, $\varepsilon_{i 0}, \varepsilon_{i n q}$, and $\varepsilon_{i n v}$, capture randomness in performance. In order to identify the loadings on ability we rely on the following standard assumption in the literature on Factor Models.

Assumption 4.1 The factors $\theta_{i}, \varepsilon_{i 0}, \varepsilon_{i n q}$, and $\varepsilon_{i n v}$ are orthogonal to each other and to the observables.

\footnotetext{
${ }^{12}$ As the astute reader would notice, the selection on the basis of $\theta_{i}$ operates through the same channels as the selection on the basis of $\varepsilon_{i 0}$. However, these two sources of selection differ when students are below the cutoff so that even if there is no selection on $\varepsilon_{i 0}$, there could be selection on $\theta_{i}$.
} 
Figure 3 summarizes our estimation strategy, starting with first time takers on the left hand side of the diagram. In Turkey, practically every high school senior takes the university entrance exam. For this reason, the sub-sample of first time takers is free of selection. In this sub-sample, we can estimate the system of performance equations given in the box for first time takers.

Figure 3: Estimation Strategy
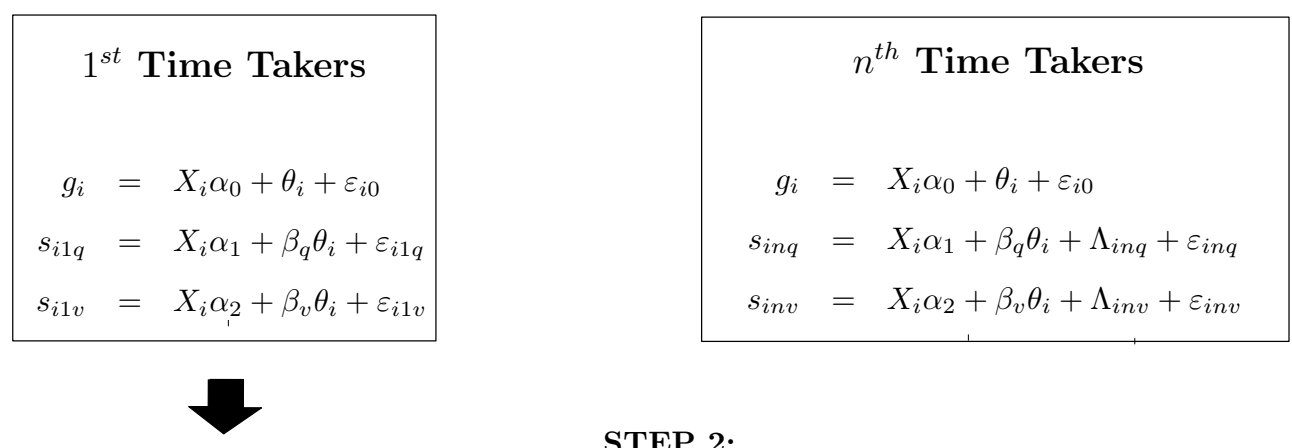

\section{STEP 2:}

STEP 1: $\quad \hat{\alpha}_{0}, \hat{\alpha}_{1}, \hat{\alpha}_{2}$ $\hat{\beta}_{q}, \hat{\beta}_{v}$

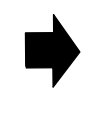

$$
\begin{aligned}
r_{g} & =g_{i}-X_{i} \hat{\alpha}_{0}=\theta_{i}+\varepsilon_{i 0} \\
r_{s_{q}} & =s_{i n q}-X_{i} \hat{\alpha}_{1}=\hat{\beta}_{q} \theta_{i}+\Lambda_{i n q}+\varepsilon_{i n q} \\
r_{s_{v}} & =s_{i n v}-X_{i} \hat{\alpha}_{2}=\hat{\beta}_{v} \theta_{i}+\Lambda_{i n v}+\varepsilon_{i n v}
\end{aligned}
$$

STEP 3:

$$
\begin{aligned}
& E\left(r_{s_{q}}-\hat{\beta}_{q} r_{g} \mid N_{i}=n\right)=E\left(\Lambda_{i n q}-\hat{\beta}_{q} \varepsilon_{i 0} \mid N_{i}=n\right) \approx E\left(\Lambda_{i n q} \widehat{N}_{i}=n\right) \\
& E\left(r_{s_{v}}-\hat{\beta}_{v} r_{g} \mid N_{i}=n\right)=E\left(\Lambda_{i n v}-\hat{\beta}_{v} \varepsilon_{i 0} \mid N_{i}=n\right) \approx E\left(\Lambda_{i n v} \widehat{N}_{i}=n\right) \\
& \text { STEP 4: }
\end{aligned}
$$$$
E\left(\Lambda_{i n} \widehat{N}_{i}=n\right)=\omega_{q} E\left(\Lambda_{i n q} \widehat{N}_{i}=n\right)+\omega_{v} E\left(\Lambda_{i n v} \widehat{N}_{i}=n\right)
$$

As there is no learning among first time takers, the correlation between error terms across the three performance equations is driven by students' unobservables. This allows us to obtain $\hat{\alpha}_{0}, \hat{\alpha}_{1}, \hat{\alpha}_{2}$ using ordinary least squares to separately estimate each performance equation in the 
sample of first time takers 13 Let $r_{g}, r_{s_{q}}$, and $r_{s_{v}}$ denote the residuals from the three performance equations. These residuals, given in step 2 in Figure 3, contain both the effect of unobservables and random shocks to performance.

It can easily be seen that:

$$
\begin{aligned}
E\left(r_{g}^{2}\right) & =E\left(\theta^{2}+\varepsilon_{0}^{2}\right)=\sigma_{\theta}^{2}+\sigma_{\varepsilon_{0}}^{2} \\
E\left(r_{s_{q}}^{2}\right) & =E\left(\beta_{q}^{2} \theta^{2}+\varepsilon_{1 q}^{2}\right)=\beta_{q}^{2} \sigma_{\theta}^{2}+\sigma_{\varepsilon_{1 q}}^{2} \\
E\left(r_{s_{v}}^{2}\right) & =E\left(\beta_{v}^{2} \theta^{2}+\varepsilon_{1 v}^{2}\right)=\beta_{v}^{2} \sigma_{\theta}^{2}+\sigma_{\varepsilon_{1 v}}^{2} \\
E\left(r_{g} r_{s_{q}}\right) & =E\left[\left(\theta+\varepsilon_{0}\right)\left(\beta_{q} \theta+\varepsilon_{1 q}\right)\right]=\beta_{q} \sigma_{\theta}^{2} \\
E\left(r_{g} r_{s_{v}}\right) & =E\left[\left(\theta+\varepsilon_{0}\right)\left(\beta_{v} \theta+\varepsilon_{1 v}\right)\right]=\beta_{v} \sigma_{\theta}^{2} \\
E\left(r_{s_{q}} r_{s_{v}}\right) & =E\left[\left(\beta_{q} \theta+\varepsilon_{1 q}\right)\left(\beta_{v} \theta+\varepsilon_{1 v}\right)\right]=\beta_{q} \beta_{v} \sigma_{\theta}^{2}
\end{aligned}
$$

Solving this system of equations allows us to identify factors' variances and loadings nonparametrically 14 Table C.3 in Appendix C reports these estimates from which we only require $\hat{\beta}_{q}$ and $\hat{\beta}_{v}$ to measure learning.

With $\hat{\alpha_{0}}, \hat{\alpha_{1}}, \hat{\alpha_{2}}, \hat{\beta}_{q}$, and $\hat{\beta}_{v}$ we can then move forward to steps 2, 3 and 4 in Figure 3. In step 2 we use these estimates to back out $\theta+\varepsilon_{i 0}$ for each agent. This is a noisy estimate of ability at the individual level. However, given the pattern of selection shown in Sub-Section 4.1 , when agents are patient enough $E\left[\theta_{i}+\varepsilon_{i 0} \mid N_{i}=n\right]$ yields an upper bound of the effect of $\theta_{i}$ on performance for $N_{i}=n$, which implies that the estimates we provide are a lower bound of the learning effect.

In step 3 , we use this noisy estimate weighted by $\hat{\beta}_{j}$ and subtract it from $r_{s_{j}} \forall j=\{q, v\}$. In other words, the difference between the score and the predicted score based on observables and the noisy estimate of $\theta$ will give us our estimate of learning between the first and the $n^{\text {th }}$ attempt. Notice that, since we allowed the learning shocks distribution to depend on $X_{i}$, we

\footnotetext{
${ }^{13}$ Full results are shown in Table C.2 in Appendix C

${ }^{14}$ (12) divided by (11) yields $\hat{\beta}_{q}$. The ratio of (10) to $\hat{\beta}_{q}$ yields $\hat{\sigma}_{\theta}^{2}$ while the ratio of (11) to $\hat{\sigma}_{\theta}^{2}$ yields $\hat{\beta}_{v}$. The difference between (77) and $\hat{\sigma}_{\theta}^{2}$ gives us $\hat{\sigma}_{0}^{2}$. Similarly, the differences between (8) and $\hat{\beta}_{q}{ }^{2} \hat{\sigma}_{\theta}^{2}$ and (9) and $\hat{\beta}_{v}{ }^{2} \hat{\sigma}_{\theta}^{2}$ yield $\hat{\sigma}_{\varepsilon_{1 q}}^{2}$ and $\hat{\sigma}_{\varepsilon_{1 v}}^{2}$, respectively.
} 
can also identify heterogeneous learning effects by conditioning both on $N_{i}$ and background variables.

The approach described above will work well if $E\left(\varepsilon_{i 0} \mid N_{i}=n\right)$ is small. We carry out simulations to confirm that the bias coming from selection on $\varepsilon_{i 0}$ is very close to zero (see SubSection 5.2). Before proceeding to our results, we would like to emphasize that we estimate cumulative learning for all $n$ but cannot estimate learning between attempts. This comes from further selection occurring for students who keep retaking 15

\section{Results}

Table 1 presents the estimated average cumulative learning gains for repeat takers in terms of their absolute improvement in points. We find that cumulative learning gains on the first retry are quite similar across tracks and amount to about $5 \%$ of the average predicted score on their first attempt. While in the Science track cumulative learning remains at roughly the same level across attempts, Social Studies and Turkish-Math exhibit cumulative learning gains that are increasing in the number of attempts. By the fifth attempt, students from Social Studies and Turkish-Math tracks record learning gains of up to $14 \%$ and $10 \%$ of their initial predicted score, respectively. Moreover, as Figure 4 shows, learning gains are critical for crossing the 120 point threshold in Social Studies and Turkish-Math tracks while they are not that crucial for the average repeat taker in the Science track.

\subsection{Learning, Selection, and Composition Revisited}

As explained earlier, the change in the distribution of scores across attempts presented in Figure 1 is driven both by selection and learning within each track. Table 2 decomposes $E\left(s_{i n} \mid N_{i}=\right.$ $n)-E\left(s_{i 1} \mid N_{i}=1\right)$ into selection due to $X_{i}, \theta_{i}$ and learning, to get a better idea of their relative importance by track.

In the Science track, the first row, labelled $E\left(s_{i n} \mid N_{i}=n\right)-E\left(s_{i 1} \mid N_{i}=1\right)$, shows that repeat

\footnotetext{
${ }^{15}$ Students are forward-looking and know their future learning shocks, which means that students with higher $\Lambda_{\text {in } \mathrm{S}}$ will retake more times. This implies that the difference between cumulative learning in attempts $n$ and $(n+1)$ will contain selection into retaking based on learning itself.
} 
Table 1: $E\left(\widehat{\Lambda_{i n} \mid N_{i}}=n\right)$ by Track

\begin{tabular}{lccc} 
Attempts & Science & Social Studies & Turkish-Math \\
\hline$n=2$ & 6.724 & 6.032 & 5.867 \\
& $(0.233)$ & $(0.263)$ & $(0.159)$ \\
$n=3$ & 6.624 & 10.160 & 8.980 \\
& $(0.341)$ & $(0.302)$ & $(0.219)$ \\
$n=4$ & 7.052 & 12.601 & 10.073 \\
& $(0.414)$ & $(0.354)$ & $(0.358)$ \\
$n \geq 5$ & 4.893 & 15.211 & 10.822 \\
& $(0.475)$ & $(0.423)$ & $(0.574)$ \\
\hline
\end{tabular}

Figure 4: Improvement in Gap from $s_{*}$ by Track

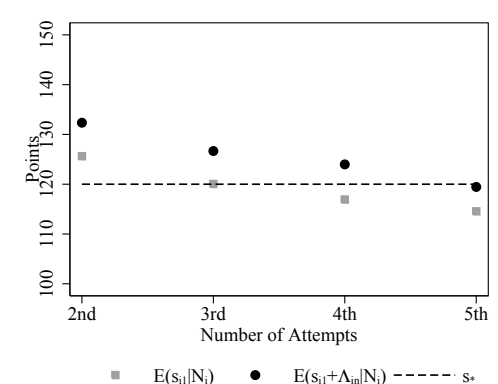

(a) Science

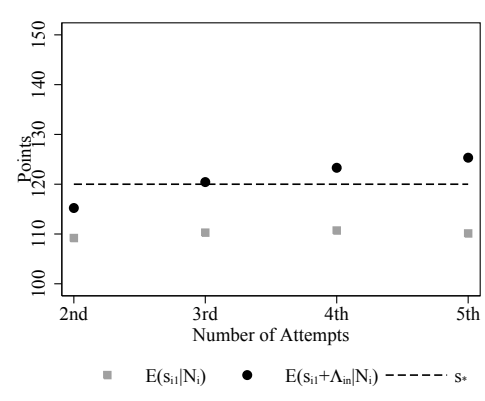

(b) Social Studies

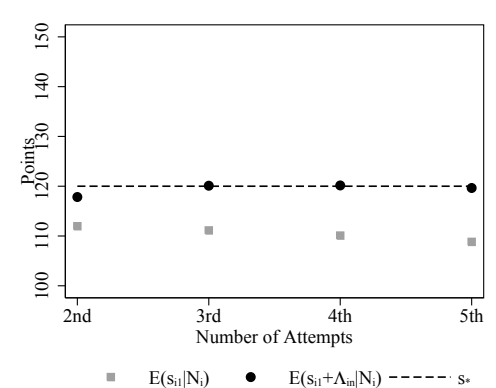

(c) Turkish-Math

takers seem to be doing worse than first time takers on average, i.e., the density in Figure 1 moves backwards. The table shows that this is due to negative selection in terms of $X_{i}$ and $\theta_{i}$ despite the presence of positive learning, which suggests that students from disadvantaged backgrounds tend to retake more in this track. Moreover, selection in terms of $X_{i}$ is far more important than selection in terms of unobservables and its role increases with $n$.

Among Social Studies students, $E\left(s_{i n} \mid N_{i}=n\right)-E\left(s_{i 1} \mid N_{i}=1\right)>0$ and almost all of the improvement in scores over attempts is explained by the learning gains accruing to repeat takers. Selection in terms of $\theta_{i}$ and $X_{i}$ is small. This is not surprising given the high proportion of repeat takers in this track. In the Turkish-Math track the distribution of scores also shifts 
to the right across attempts, though less so than in Social Studies. However, there are nonnegligible negative selection effects on $X_{i}$ and $\theta_{i}$ in this track, which results in learning gains being larger than the mean score improvement would suggest.

Table 2: Decomposition of $E\left(s_{i n} \mid N_{i}=n\right)-E\left(s_{i 1} \mid N_{i}=1\right)$ by the contribution of $X_{i}, \theta_{i}$, and $\Lambda_{i n}$

\begin{tabular}{lcccc} 
& \multicolumn{4}{c}{ Number of Attempts } \\
\cline { 2 - 5 } & $n=2$ & $n=3$ & $n=4$ & $n \geq 5$ \\
\hline Science & & & & \\
$E\left(s_{i n} \mid N_{i}=n\right)-E\left(s_{i 1} \mid N_{i}=1\right)$ & -2.3 & -10.8 & -15.2 & -18.7 \\
$\Delta$ due to $X_{i}$ & -7.0 & -12.6 & -15.7 & -18.1 \\
$\Delta$ due to $\theta_{i}$ & -1.9 & -4.8 & -6.5 & -5.5 \\
$\Delta$ due to $\Lambda_{i n}$ & 6.7 & 6.6 & 7.1 & 4.9 \\
Social Studies & & & & \\
$E\left(s_{i n} \mid N_{i}=n\right)-E\left(s_{i 1} \mid N_{i}=1\right)$ & 6.5 & 12.1 & 15.4 & 17.5 \\
$\quad \Delta$ due to $X_{i}$ & -0.3 & 0.8 & 1.2 & 0.6 \\
$\Delta$ due to $\theta_{i}$ & 0.8 & 1.1 & 1.6 & 1.7 \\
$\Delta$ due to $\Lambda_{i n}$ & 6.0 & 10.2 & 12.6 & 15.2 \\
Turkish-Math & & & & \\
$E\left(s_{i n} \mid N_{i}=n\right)-E\left(s_{i 1} \mid N_{i}=1\right)$ & 2.8 & 3.3 & 3.2 & 3.4 \\
$\Delta$ due to $X_{i}$ & -2.7 & -3.5 & -4.6 & -5.8 \\
$\Delta$ due to $\theta_{i}$ & -0.4 & -2.2 & -2.4 & -1.6 \\
$\Delta$ due to $\Lambda_{i n}$ & 5.9 & 9.0 & 10.1 & 10.8 \\
\hline
\end{tabular}

Note that Table 2 offers clear support to the argument that it is critical to allow for unobservables as we do here. Had we not done so, our results would have been biased, especially in the Science and Turkish-Math tracks. Given $E\left[\widehat{\theta_{i} \mid N_{i}}=n\right]<0 \forall n>1$ in these tracks, correcting for selection into retaking only on $X_{i}$ would underestimate learning since leaving selection on $\theta_{i}$ out of the picture results in a higher predicted initial score among repeat takers.

Having identified mean learning gains among repeat takers, we ask whether these differ by background. Figure 5 reports the estimated learning gap between advantaged and disadvantaged students in each track. The former are defined as applicants in the highest income group (above 500 TL) or those who attended Anatolian or Science high schools. These are the elite high 
Figure 5: Learning Gap Between Advantaged and Disadvantaged Students by Track

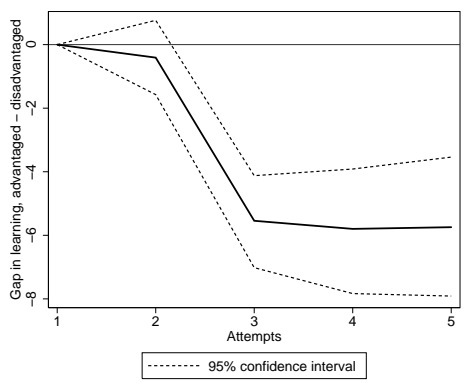

(a) Science

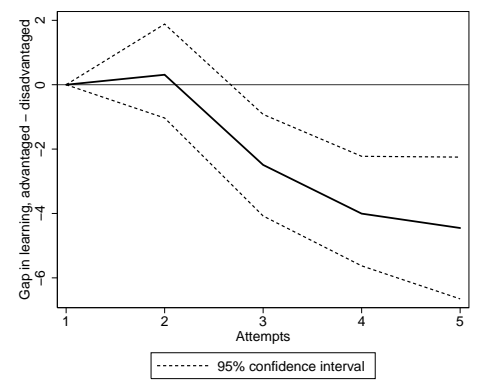

(b) Social Studies

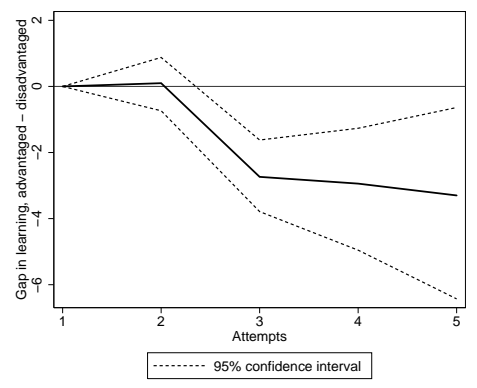

(c) Turkish-Math

schools in Turkey, which require an admission exam 16 The latter are those in the lowest income group (below 250 TL) and who graduated from public high schools. Except for a negligible gap in the sub-sample of second time takers, it is clear that less advantaged students learn much more than advantaged ones and that this gap increases with the number of attempts, irrespective of the track. This common pattern across tracks is worth emphasizing 17

In sum, we identify large learning effects and these are particularly prevalent among repeat takers with less advantaged backgrounds. Thus, retaking may be a way for less prepared students to catch up before they go to college.

\subsection{Simulations}

Our estimates of learning in Section 5 are unbiased if $E\left[\varepsilon_{i 0} \mid N_{i}=n\right]$, the expected value of the GPA shock conditional on taking the exam $n$ times, is zero. As we argued in Section 4.1. students with high $\varepsilon_{i 0}$ accept placement, while those with low $\varepsilon_{i 0}$ quit so that selection

\footnotetext{
${ }^{16}$ Thus, our definition of "advantaged" students includes those who have access to better educational inputs, both through higher family income or higher quality education.

${ }^{17} \mathrm{~A}$ concern that the perceptive reader might have is that our results on heterogenous learning are coming from another form of selection. Namely that the advantaged are more likely to retake than the disadvantaged. This could occur if they face lower costs of retaking or if their discount factors are higher. As a result, their learning between retakes could look smaller. To check if this was the case we looked at the probability of retaking and we found similar retaking rates across groups that were differentially advantaged.
} 
truncates the distribution of $\varepsilon_{i 0}$ among retakers both from above and below. The truncation from above makes $E\left[\varepsilon_{i 0} \mid N_{i}=n\right]$ negative which results in learning effects being overestimated while truncation from below works in the opposite way. Truncation from above vanishes as students get more patient. In this section, we use simulations to demonstrate that the bias coming from $\epsilon_{i 0}$ tends to be small even when students are impatient.

We set up and simulate a dynamic decision model with the following structure:

1. A student is born with perfect knowledge of his GPA $g_{i}$, ability $\theta_{i}$, and all future learning shocks $\Lambda_{i n}$.

2. The student takes the entrance exam and learns his $\varepsilon_{i n}$.

3. If the student's score is above the placement threshold (120 points), he decides whether to be placed. Placement is the terminal state; the utility from placement equals $\left(s_{i}+\eta g_{i}\right)$.

4. If the student is below the threshold or chooses not to be placed, he learns the value of quitting, $V Q_{\text {in }}=V Q_{0}+\xi_{\text {in }}$, and chooses between quitting and retaking 18 Quitting is the terminal state. Retaking is costly: (i) all retakers pay $\psi_{n}$ before the next attempt, and (ii) the value of retaking is discounted at a rate $\delta$.

5. Steps $2-4$ are repeated for students who choose to retake.

6. The option to retake disappears after the 10th attempt 19

In our simulations, for simplicity, students do not differ in observables $X_{i}$. We simulate GPA and noise-free scores by independently drawing $\varepsilon_{i 0}, \theta_{i}$ and $\lambda_{i n}$ from normal distributions with parameters given in Table 3. We then substitute these draws into:

$$
g_{i}=E\left[\widehat{g_{i} \mid N_{i}}=1\right]+\theta_{i}+\varepsilon_{i 0}, \quad \bar{s}_{i n}=\widehat{E\left[s_{i 1}\right]}+\left(\omega_{q} \hat{\beta}_{q}+\omega_{v} \hat{\beta}_{v}\right) \theta_{i}+\sum_{k \leq n} \lambda_{i k}
$$

\footnotetext{
${ }^{18}$ We need randomness in $V Q$ in order to make the simulated number of retakers smooth in the model's parameters. This makes it easier to calibrate the model. The shock $\xi_{\text {in }}$ is drawn from the standard normal distribution.

${ }^{19}$ We choose to shut down the option of retaking rather than extending the time periods indefinitely and assuming stationarity since most people stop retaking after three or four attempts. We do not expect our choice in this matter to affect our results.
} 
where $E\left[\widehat{g_{i} \mid N_{i}}=1\right]$ is the mean GPA among all first time takers. $\widehat{E\left[s_{i 1}\right]}$ is the mean exam score

Table 3: Parameter values used in the simulations

\begin{tabular}{|c|c|c|c|c|}
\hline & Science & $\begin{array}{r}\text { Social } \\
\text { Studies }\end{array}$ & $\begin{array}{r}\text { Turkish- } \\
\text { Math }\end{array}$ & Source \\
\hline$E\left[\theta_{i}\right]$ & & 0 & & By construction \\
\hline$E\left[\varepsilon_{i n}\right] \forall n \geq 0$ & & 0 & & By construction \\
\hline$\sigma_{\theta}$ & 7.75 & 6.32 & 6.56 & Estimates \\
\hline$\sigma_{\varepsilon_{0}}$ & 5.53 & 6.74 & 6.75 & Estimates \\
\hline$\sigma_{\varepsilon_{n}} \forall n>0$ & 8.51 & 7.91 & 4.23 & Estimates \\
\hline$s_{*}$ & & 120 & & ÖSS Rules \\
\hline$\eta$ & & 0.5 & & ÖSS Rules \\
\hline$E\left[\lambda_{i 2}\right]$ & 6.72 & 6.03 & 5.87 & Assumption $^{a /}$ \\
\hline$E\left[\lambda_{i 3}\right]$ & -0.10 & 4.13 & 3.11 & Assumption \\
\hline$E\left[\lambda_{i 4}\right]$ & -0.43 & 2.44 & 1.09 & Assumption \\
\hline$E\left[\lambda_{i 5}\right]$ & -2.16 & 2.61 & 0.75 & Assumption \\
\hline$E\left[\lambda_{i n}\right] \forall n>5$ & & 0 & & Assumption \\
\hline$\sigma_{\lambda_{i n}} \forall n=2 \ldots 5$ & & 10 & & Assumption \\
\hline$\sigma_{\lambda_{i n}} \forall n>5$ & & 0 & & Assumption \\
\hline$V Q_{0}$ & & 0 & & Assumption \\
\hline$\psi_{2}, \psi_{3}, \psi_{4}$ & & depend on $\delta$ & & Calibration \\
\hline$\psi_{5}=\cdots=\psi_{10}$ & & depend on $\delta$ & & Calibration \\
\hline
\end{tabular}

for first time takers. To be specific, $g_{i}$ is generated by taking the mean GPA from the data, and drawing $\theta_{i}$ and $\varepsilon_{i 0}$. The noise-free component of $s_{i n}, \bar{s}_{i n}$, is generated by taking the mean score among first time takers, and drawing $\theta_{i}$ and $\lambda_{i k} \forall k \leq n$. The ability shock is then weighted using known parameters $\omega_{q}$ and $\omega_{v}$ and our estimates of $\hat{\beta}_{q}$ and $\hat{\beta}_{v}$ in each track.

We then solve the dynamic decision problem for each student starting from the 10th attempt. At this point the student can either be placed or quit. Students who draw high scores are placed while the remainder quit. The distribution of $\varepsilon_{i 10}$ gives the probabilities of being placed and quitting for the last attempt. Working backwards, a similar procedure gives the probabilities of retaking, being placed, and quitting for every $i$ and $n$ in a given iteration.

In each track, we draw a data set of as many individuals as the number of first time takers in 
the actual data. Of course, individuals in the simulated data differ only in terms of their random shocks and unobservables. We then calibrate $\psi_{n}$ and $V Q_{0}$ to target the number of repeat takers in each attempt and the total number of quitters in early rounds in the actual data 20 After calibrating the model, we use it to simulate 1000 artificial data sets and find the median bias in our estimate of $E\left[\Lambda_{i n} \mid N_{i}=n\right]$ by track and number of attempts. Recall that the bias is $-\left(\omega_{q} \hat{\beta}_{q}+\omega_{v} \hat{\beta}_{v}\right) E\left[\varepsilon_{i 0} \mid N_{i}=n\right]$. We repeat this exercise for a range of discount factor values from 0.1 to 1 . The 5 th, 50 th and 95 th percentiles of the simulated bias are plotted in Figure 6 .

The bias is affected by two forces that work against each other. On the one hand, students with high $\varepsilon_{i 0}$ 's cash them in and get placed. This pushes $E\left[\epsilon_{i 0} \mid N_{i}=n\right]$ down and upward biases our learning estimates. On the other hand, quitting is more likely for students with low $\epsilon_{i 0}$ 's. This raises the average $\epsilon_{i 0}$ among repeat takers, making the learning bias negative. The former effect is larger when students are impatient and thus the bias falls as $\delta$ rises. As explained earlier, we expect no bias due to selection on $\epsilon_{i 0}$ from above when $\delta$ is close to one. If this is true, our learning bias must be non-positive at $\delta=1$. This is clearly the case in the simulations.

Our simulations suggest the bias does exist, but its magnitude is substantially smaller than any estimate of learning that we report in Tables 1 and 2. It is also worth noting that for reasonable levels of patience (i.e., $\delta>0.9$ ) the bias in our learning estimates tends to be negative so that we can think of them as a lower bound.

\section{Conclusions and Proposed Agenda}

Most people would agree that levelling the playing field in the educational arena is desirable. In different settings, different approaches are taken with this objective in mind: minority preferences, quotas, remedial classes, scholarships, and so on. Preferential policies may however create their own difficulties if admitted students fall further behind. Our work suggests that giving second chances, without lowering standards, in an exam-based system may offer a way to help the disadvantaged as they seem to learn more over attempts.

\footnotetext{
${ }^{20}$ We choose to match quitting patterns in attempts $1-3$ as the terminal period becoming closer creates distortions in the simulated moments.
} 
Figure 6: Simulated Bias in $E\left(\widehat{\Lambda_{i n} \mid N_{i}}=n\right)$ by Number of Attempts and Track
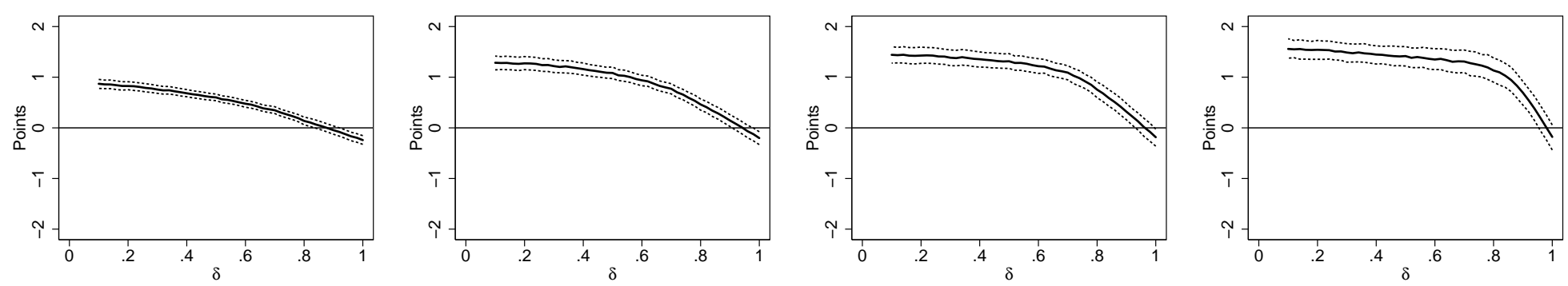

(a) Science
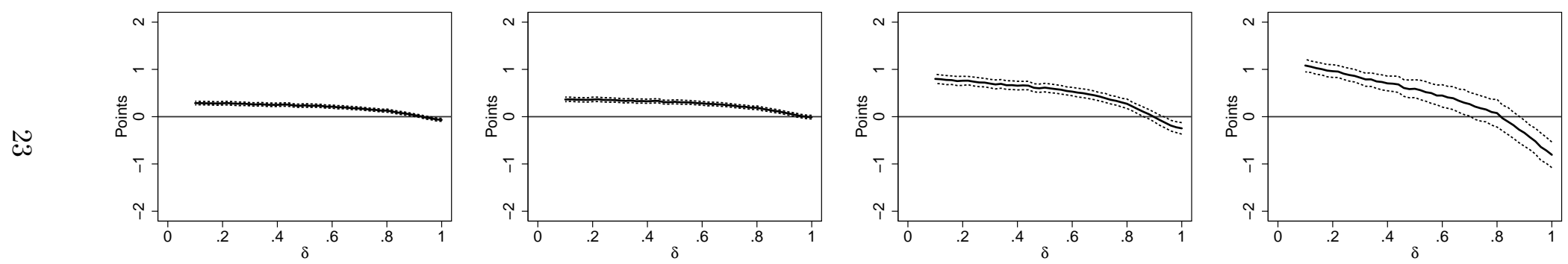

(b) Social Studies
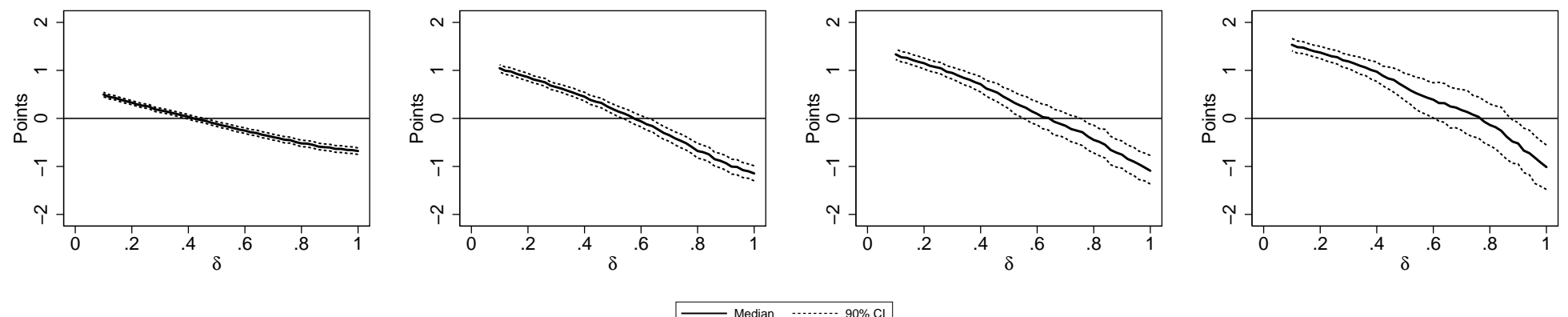

(c) Turkish-Math
(a) $n=2$
(b) $n=3$
(c) $n=4$
(d) $n \geq 5$ 
One of the limitations of our paper is that we do not fully estimate the model outlined in Section 4. Consequently, we cannot say much about what happens between attempts or measure the net welfare impact of letting students retake the ÖSS and other counterfactuals. We are currently working on a dynamic structural model that will allow us to measure marginal learning as well as to evaluate the effects of different policy interventions such as setting a maximum number of attempts. A second limitation is the known ability assumption. This is still an open question that cannot be tackled with a cross-section data set. In this case, panel data is required to disentangle learning about own ability and learning about the content of the exam. 


\section{References}

Arcidiacono, Peter, Esteban Aucejo, and Spenner Ken (2012) 'What Happens After Enrollment? An Analysis of the Time Path of Racial Differences in GPA and Major Choice.' IZA Journal of Labor Economics 5(1), 1-25.

Caner, Asena, and Cagla Okten (2010) 'Risk and Career Choice: Evidence from Turkey.' Economics of Education Review 29(6), 1060-1075.

- (2013) 'Higher education in Turkey: Subsidizing the rich or the poor?' Economics of Education Review 35, 75-92.

Card, David (2005) 'Is the New Immigration Really so Bad?' The Economic Journal 115(506), F300-F323.

Carneiro, Pedro, Karsten Hansen, and James Heckman (2003) 'Estimating Distributions of Treatment Effects with an Application to the Returns to Schooling and Measurement of the Effects of Uncertainty on College.' NBER Working Papers 9546

Cooley, Jane, Salvador Navarro, and Takahashi Yuya (2011) 'How the Timing of Grade Retention Affects Outcomes: Identification and Estimation of Time-Varying Treatment Effects.' Working paper.

Frisancho, Veronica, and Kala Krishna (2012) 'Affirmative Action in Higher Education in India: Targeting, Catch Up, and Mismatch.’ NBER Working Paper No. 17727.

Loury, Linda Datcher, and David Garman (1993) 'Affirmative Action in Higher Education.' American Economic Review 83(2), 99-103.

- (1995) 'College Selectivity and Earnings.' Journal of Labor Economics 13(2), 289-308. University of Chicago Press.

Nathan, Julie, and Wayne Camara (1998) 'Score Change When Retaking the SAT I: Reasoning Test.' Research Notes, The College Board, Office of Research and Development.

Portes, Alejandro, and Ruben Rumbaut (2001) Legacies: The Story of the Immigrant Second Generation (Berkeley: University of California Press.)

Sander, Richard (2004) 'A Systemic Analysis of Affirmative Action in American Law Schools.' Stanford Law Review 57(2), 367-483.

Saygin, Perihan (2011) 'Gender Differences in College Applications: Evidence from the Centralized System in Turkey.' Working paper.

Tansel, Aysit, and Fatma Bircan (2005) 'Effect of Private Tutoring on University Entrance Examination Performance in Turkey.' IZA Discussion Paper, No. 1609.

Türk Eğitim Derneği (TED or Turkish Educational Association) (2005) 'Study on the University Placement System in Turkey and Suggestions for Solution.' http://eua.cu.edu.tr/files/ turkiyeninyuksekogretimstratejisi.pdf. The Council of Higher Education (YÖK).

Vigdor, Jacob L., and Charles T. Clotfelter (2003) 'Retaking the SAT.' The Journal of Human Resources 38(1), 1-33. 


\section{A ÖSYM and the Higher Education Placement Process}

The ÖSS tests student knowledge in four subjects: Mathematics, Turkish, Science, and Social Studies 21 Each section of the exam is composed of 45 multiple choice questions which are worth one point for each correct answer and -0.25 for each incorrect answer. ÖSYM calculates raw scores in each subject as well as two summary scores: raw verbal (raw Turkish and Social Studies) and raw quantitative (raw Science and Math). These six raw scores are standardized with mean 50 and standard deviation 10. These standard scores are then used to construct three weighted scores:

Weighted-Verbal $=(1.8) *($ Standard-Verbal $)+(0.4) *($ Standard-Quantitative $)$,

Weighted-Quantitative $=(1.8) *($ Standard-Quantitative $)+(0.4) *($ Standard-Verbal $)$, and

Weighted-Average $=(0.8) *($ Standard-Turkish + Standard-Math $)+(0.3) *($ Standard-Science + Standard-Social Studies ).

For each weighted score exceeding 105 points, a placement score is calculated for the student: Placement-Verbal, Placement-Quantitative, and Placement-Average. The placement scores are constructed by adding the weighted standardized high school GPAs, denoted by "wsGPA", to the relevant weighted scores. The wsGPAs are constructed in a way to ensure that students will choose a field of study compatible with their high school track. As mentioned in Section 3. the available tracks in most high schools are Science, Social Studies, and Turkish-Math. The relevant scores for each of these tracks are Quantitative, Verbal and Average, respectively.

Calculating the wsGPAs is a complicated process. First, students' GPAs are standardized using the GPA distribution in their high school to obtain sGPAs 22 For each student, three weighted standardized GPAs (wsGPA, $\mathrm{wsGPA}_{Q}$, and $\mathrm{wsGPA}_{A}$ ), one for each weighted score, are constructed according to the performance of the students' high school in the relevant score. Finally, these wsGPAs are added with a weight of 0.5 when the placement score type matches the student's high school track and a weight of 0.2 otherwise. For instance, placement scores for a Science track student are calculated as:

Placement-Verbal $=$ Weighted-Verbal $+(0.2) * w s G P A_{V}$

Placement-Quantitative $=$ Weighted-Quantitative $+(0.5)^{*} w s G P A_{Q}$, and

Placement-Average $=$ Weighted-Average $+(0.2) * w s G P A_{A}$.

Each field of study will assign seats to students on the basis of the relevant placement score. For instance, a seat in a History program is based on Placement-Verbal score while a seat in an engineering program is rationed on the basis of Placement-Quantitative scores. Qualified

\footnotetext{
${ }^{21}$ There is also a Foreign Language Test (YDS), administered separately from the ÖSS. However, only students who are interested in careers that rely on the acquisition of a foreign language have to take this exam. In 2002 , only around 40,000 students took this test. For that reason, we do not take the YDS into account in our analysis.

${ }^{22}$ Student $i$ 's sGPA score is obtained in the following way:

$$
\mathrm{sGPA}_{i}=10\left(\frac{\mathrm{GPA}_{i}-\mu}{\sigma}\right)+50
$$

where $\mu$ and $\sigma$ are the mean and standard deviation of raw GPAs in student $i$ 's high school. sGPAs are calculated the first time a student takes the ÖSS, relative to the students graduating from his high school in that year, and they are not updated over repeated attempts.
} 
students can list up to 18 four-year programs on their preference lists in addition to 6 two-year programs. Before a student submits his placement preferences, he has access to all his scores, his percentiles for each score, and the previous year's minimum and maximum scores for each university program.

\section{B Standardized HS GPA versus quality normalized HS GPA}

Raw and standardized GPAs ignore potential quality heterogeneity and grade inflation across high schools. Since we are interested in obtaining a measure that will allow us to rank students on the same scale based on their high school academic performance, neither of these measures are useful. Obtaining 10/10 at a very selective school is not the same as obtaining 10/10 at a very bad school.

To deal with this issue, we constructed school quality normalized GPAs. Within each track $k$ and for each school $j$, we define the adjustment factor, $A_{j k}$ :

$$
A_{j k}=\frac{\overline{\mathrm{GPA}}_{j k}}{\overline{\text { Weighted Score }}_{j k}} \div \frac{{\overline{\mathrm{GPA}}}_{k}}{\overline{\text { Weighted Score }}_{k}}
$$

where $\overline{\mathrm{GPA}}_{j k}$ and $\overline{\text { Weighted Score }}_{j k}$ are the average GPA and weighted scores for each high school and track combination. $\overline{\mathrm{GPA}}_{k}$ and Weighted Score ${ }_{k}$ are the average GPA and weighted score across all comparable students from the same track 23 The numerator in (B.1) should go up if the school is inflating grades relative to its true quality. For example, if the average GPA in school $j$ is about $8 / 10$ but the average exam score for its students is only $5 / 10$, school $j$ is worse than the raw GPAs of its students suggest. After all, since the ÖSS is a standardized exam, Weighted Score ${ }_{j k}$ should be a good proxy for the true quality of the school on a unique scale. The denominator in (B.1) is just a constant for all the students in the same database and it takes the adjustment factor to a scale that is relative to everyone in the same track.

Define the school quality normalized GPA for student $i$ in school $j$ and track $k$ as:

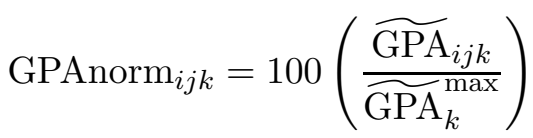

where $\widetilde{\mathrm{GPA}}_{i j k}$ is defined as:

$$
\widetilde{\mathrm{GPA}}_{i j k}=\left(\frac{\mathrm{GPA}_{i j k}}{A_{j k}}\right)
$$

and $\widetilde{\mathrm{GPA}}_{k}^{\mathrm{max}}$ is just the maximum $\widetilde{\mathrm{GPA}}_{i j k}$ in a given $k$. Notice that if the student is in a school that tends to inflate the grades relative to true performance, the raw GPA of all the students in such a school will be penalized through a higher $A_{j k}$.

\footnotetext{
${ }^{23}$ This adjustment factor is constructed using weighted quantitative scores for Science students while Social Studies students' factor relies on weighted verbal scores. For Turkish-Math students, we use the weighted average.
} 


\section{Additional Tables and Figures}

Table C.1: Descriptive Statistics

\begin{tabular}{|c|c|c|c|c|c|c|}
\hline \multirow[b]{2}{*}{ Variable } & \multicolumn{2}{|c|}{ Science } & \multicolumn{2}{|c|}{ Social Studies } & \multicolumn{2}{|c|}{ Turkish-Math } \\
\hline & Mean & S.D. & Mean & S.D. & Mean & S.D. \\
\hline \multicolumn{7}{|l|}{ Individual and Family Background } \\
\hline Gender & 0.59 & & 0.57 & & 0.51 & \\
\hline Raw HS GPA & 68.19 & 15.77 & 57.28 & 10.64 & 63.16 & 13.41 \\
\hline Standardized HS GPA & 51.68 & 10.01 & 47.66 & 7.78 & 48.99 & 8.89 \\
\hline \multicolumn{7}{|l|}{ School Type } \\
\hline Public & 0.59 & & 0.86 & & 0.71 & \\
\hline Private & 0.18 & & 0.02 & & 0.14 & \\
\hline Anatolian/Science & 0.20 & & 0.02 & & 0.11 & \\
\hline Other & 0.03 & & 0.09 & & 0.05 & \\
\hline \multicolumn{7}{|l|}{ Father's education } \\
\hline Primary or less & 0.39 & & 0.56 & & 0.44 & \\
\hline Middle/High school & 0.30 & & 0.28 & & 0.33 & \\
\hline 2-year higher education & 0.06 & & 0.03 & & 0.04 & \\
\hline College/Master/PhD & 0.17 & & 0.05 & & 0.11 & \\
\hline Missing & 0.08 & & 0.08 & & 0.09 & \\
\hline More than 3 children in the household & 0.38 & & 0.49 & & 0.39 & \\
\hline \multicolumn{7}{|l|}{ Household Monthly Income } \\
\hline$<250 \mathrm{TL}$ & 0.34 & & 0.45 & & 0.37 & \\
\hline$[250-500] \mathrm{TL}$ & 0.40 & & 0.38 & & 0.40 & \\
\hline$>500 \mathrm{TL}$ & 0.26 & & 0.17 & & 0.23 & \\
\hline \multicolumn{7}{|l|}{ Preparation for the Exam } \\
\hline Student was working when exam was taken & 0.13 & & 0.21 & & 0.10 & \\
\hline \multicolumn{7}{|l|}{ Prep school/tutoring expenditures } \\
\hline Did not attend Prep school & 0.13 & & 0.26 & & 0.19 & \\
\hline Scholarship & 0.04 & & 0.01 & & 0.01 & \\
\hline$<1 \mathrm{~b}$ TL & 0.35 & & 0.22 & & 0.31 & \\
\hline$[1-2] \mathrm{b}$ TL & 0.20 & & 0.09 & & 0.17 & \\
\hline$>2 \mathrm{~b}$ TL & 0.10 & & 0.03 & & 0.08 & \\
\hline Missing & 0.17 & & 0.38 & & 0.23 & \\
\hline \multicolumn{7}{|l|}{ Exam Performance } \\
\hline Took language exam & 0.01 & & 0.01 & & 0.01 & \\
\hline Weighted score & 124.02 & 29.99 & 113.53 & 26.61 & 113.48 & 20.82 \\
\hline \multicolumn{7}{|l|}{ Number of attempts } \\
\hline 1st attempt & 0.42 & & 0.25 & & 0.46 & \\
\hline 2nd attempt & 0.25 & & 0.25 & & 0.30 & \\
\hline 3rd attempt & 0.16 & & 0.25 & & 0.16 & \\
\hline 4 th attempt & 0.09 & & 0.16 & & 0.06 & \\
\hline 5th attempt & 0.07 & & 0.10 & & 0.02 & \\
\hline Student was placed & 0.36 & & 0.23 & & 0.26 & \\
\hline
\end{tabular}


Table C.2: Estimates of $\left[\alpha_{0}, \alpha_{1}, \alpha_{2}\right]$ by Track

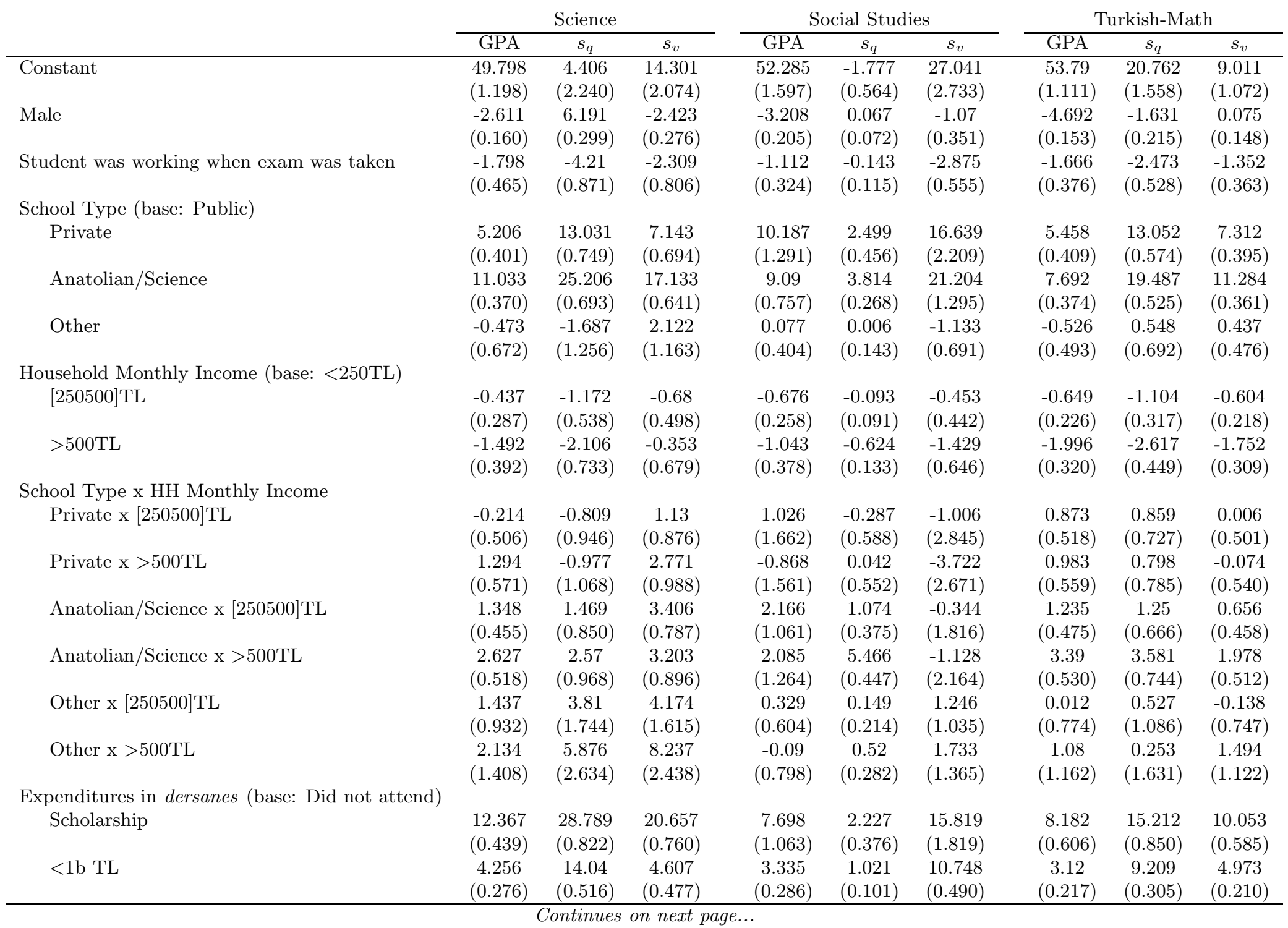


... continued from previous page

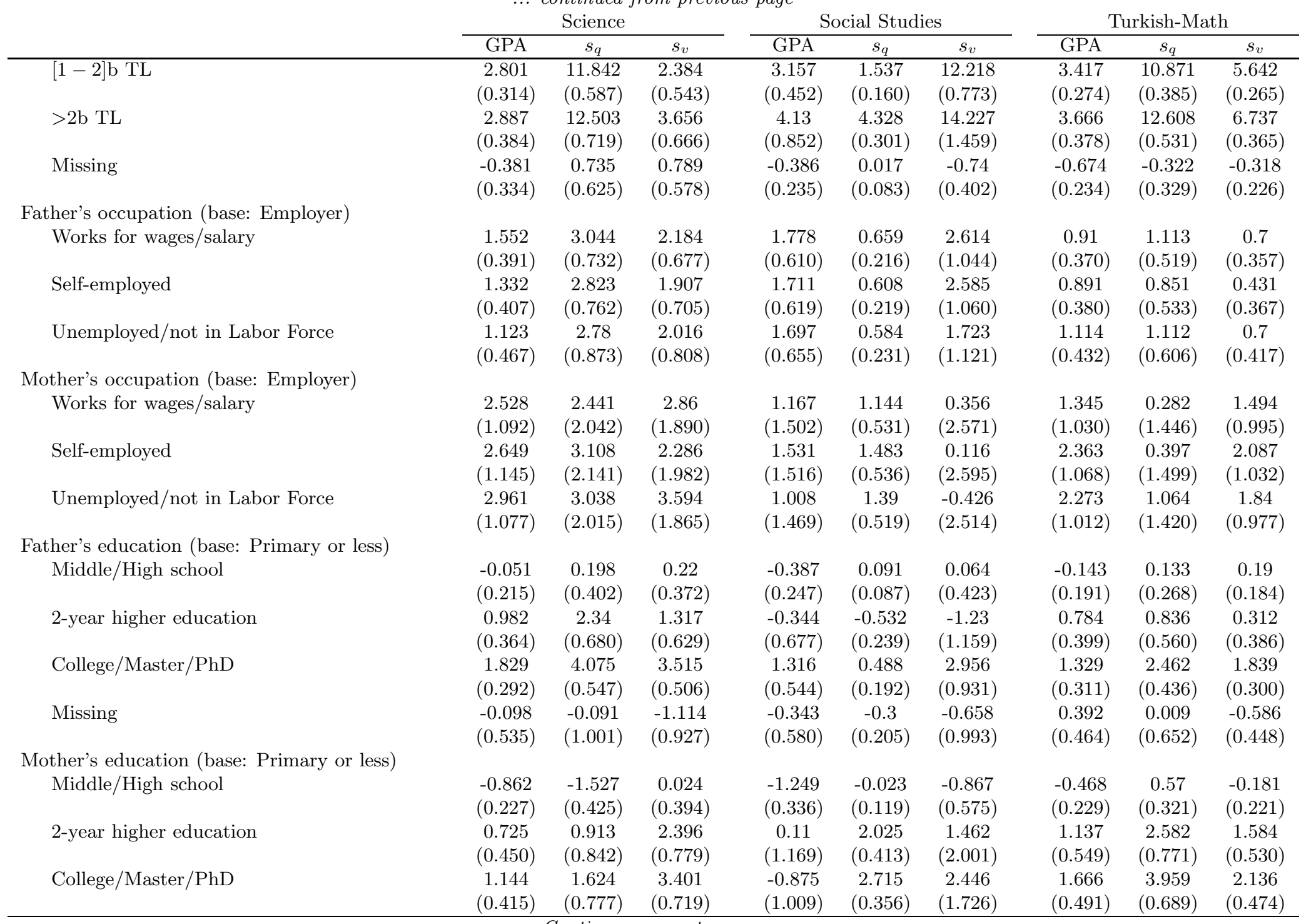

Continues on next page... 


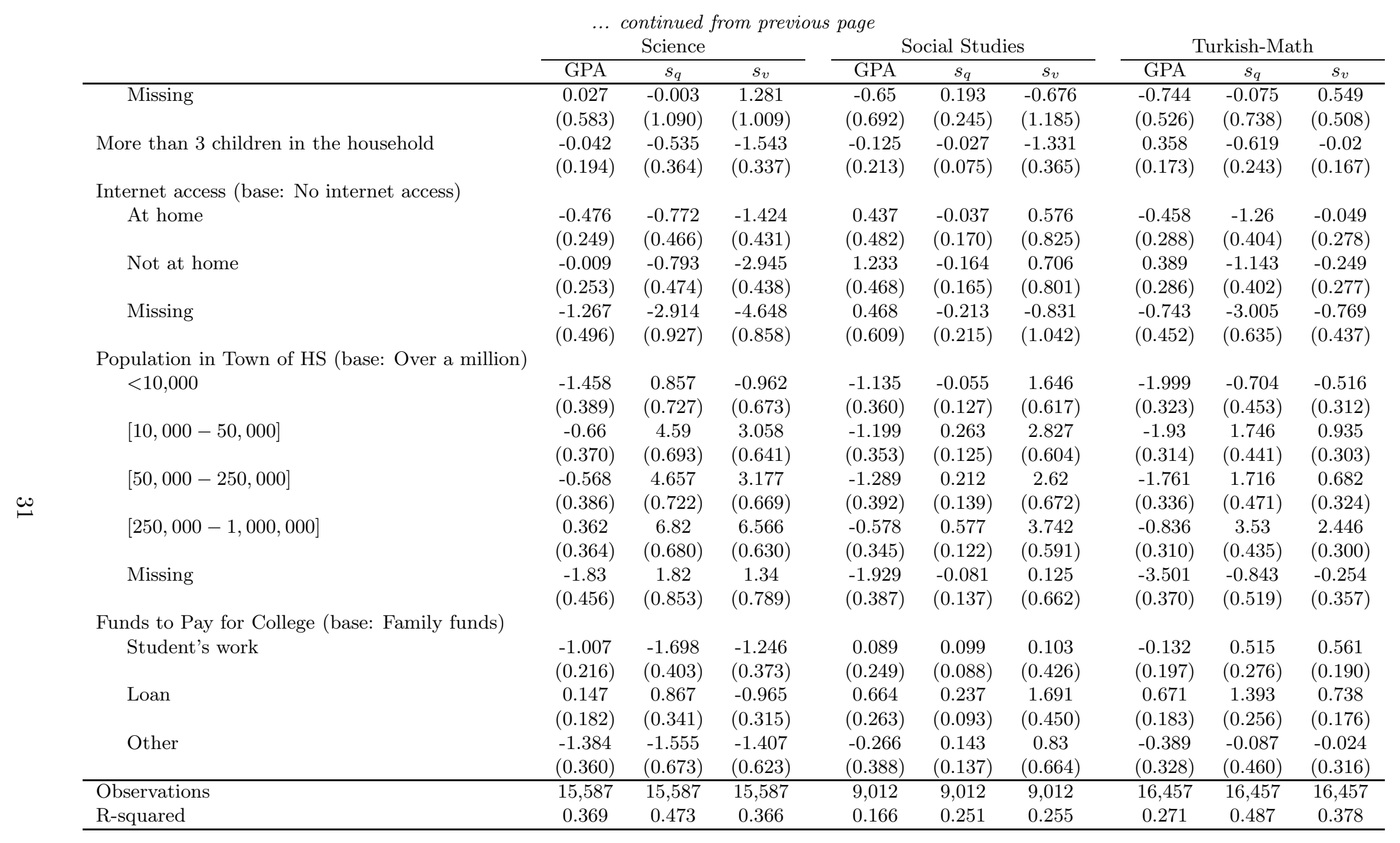


Table C.3: Estimates of Factor Variances and Loadings

\begin{tabular}{cccc} 
& Science & Social Studies & Turkish-Math \\
\hline$\hat{\beta}_{q}$ & 1.146 & 2.056 & 1.028 \\
& $(0.020)$ & $(0.112)$ & $(0.013)$ \\
$\hat{\beta}_{v}$ & 1.938 & 0.155 & 1.815 \\
& $(0.028)$ & $(0.008)$ & $(0.022)$ \\
$\hat{\sigma}_{\theta}^{2}$ & 60.023 & 39.883 & 43.035 \\
& $(1.186)$ & $(2.451)$ & $(0.936)$ \\
$\sigma_{\epsilon_{0}}^{2}$ & 30.575 & 45.362 & 45.619 \\
& $(0.970)$ & $(2.354)$ & $(0.826)$ \\
$\sigma_{\epsilon_{1 q}}^{2}$ & 91.559 & 9.686 & 32.685 \\
& $(3.140)$ & $(0.547)$ & $(1.337)$ \\
$\sigma_{\epsilon_{1 v}}^{2}$ & 192.851 & 81.176 & 37.157 \\
$\hat{\omega}_{q}$ & $(2.344)$ & $(8.839)$ & $(0.666)$ \\
& 0.844 & 0.187 & 0.670 \\
$\hat{\omega}_{v}$ & $(0.000)$ & $(0.000)$ & $(0.000)$ \\
& 0.195 & 0.876 & 0.293 \\
\hline Observations & 15,587 & 9,012 & $(0.000)$ \\
\hline
\end{tabular}

